Bing Zhang*, Xiaodi Shang, Su Yao, Qiuyu Wang, Zhijuan Zhang, Xiaokang Yang, Jun Cai and Kuaishe Wang

\title{
A Comparative Study on Johnson-Cook, Modified Johnson-Cook, Modified Zerilli-Armstrong and Arrhenius-Type Constitutive Models to Predict Hot Deformation Behavior of TA2
}

https://doi.org/10.1515/htmp-2019-0026

Received June 12, 2018; accepted November 08, 2018

Abstract: The true strain data and true stress data are obtained from the isothermal compression tests under a wide range of strain rates $\left(0.1-20 \mathrm{~s}^{-1}\right)$ and temperatures (933-1,133 K) over the Gleeble-3500 thermomechanical simulator. The data are employed to generate the constitutive equations according to four constitutive models, respectively, the strain-compensated Arrhenius-type model, the modified Zerilli-Armstrong (ZA) model, the modified Johnson-Cook (JC) model and the JC model. In the meanwhile, a comparative research was made over the capacities of these four models and hence to represent the elevated temperature flow behavior of TA2. Besides, a comparison of the accuracy of the predictions of average absolute relative error, correlation coefficient $(R)$ and the deformation behavior was made to test the sustainability level of these four models. It is shown from these results that the JC model is not suitable for the description of flow behavior of TA2 alloy in $\alpha+\beta$ phase domain, while the predicted values of modified JC model, modified ZA model and the strain-compensated

*Corresponding author: Bing Zhang, College of Metallurgy Engineering, Xi'an University of Architecture and Technology, Xi'an, China; National \& Local Engineering Researching Center for Functional Materials Processing, Xi'an, China,

E-mail: 359702589@qq.com

Xiaodi Shang: E-mail: 976387162@qq.com, Su Yao:

E-mail: 1034953262@qq.com, Qiuyu Wang:

E-mail: 474837801@qq.com, College of Metallurgy Engineering, Xi'an University of Architecture and Technology, Xi'an, China

Zhijuan Zhang, Xi'an Saite Metal Materials Development Co., LTD, Northwest Institute for Nonferrous Metal Research, Xi'an, China, E-mail: 7321969232@qq.com

Xiaokang Yang, College of Metallurgy Engineering, Xi'an University of Architecture and Technology, Xi'an, China; Xi'an Saite Metal Materials Development Co., LTD, Northwest Institute for Nonferrous Metal Research, Xi'an, China, E-mail: Yangxiaokang2000@163.com Jun Cai: E-mail: caijun0116@163.com, Kuaishe Wang:

E-mail: wangkuaishe888@126.com, College of Metallurgy

Engineering, Xi'an University of Architecture and Technology, Xi'an, China; National \& Local Engineering Researching Center for

Functional Materials Processing, Xi'an, China
Arrhenius-type model could be consistent well with the experimental values except under some deformation conditions. Moreover, the strain-compensated Arrhenius-type model can be also used to track the deformation behavior more precisely in comparison with other models.

Keywords: TA2; hot compression test; flow stress; constitutive equation

\section{Introduction}

There are broad applications of TA2 industrial pure titanium, such as chemical, ship building and aviation industry due to its strong welding property, good mechanical performance and outstanding corrosion resistance $[1,2]$. As a kind of $\alpha$-phase (hexagonal closepacked) titanium alloy at the room temperature, its poor plasticity makes cold forming cracked easily. With the increase of temperature, the slip systems in the hexagonal close-packed increase, facilitating plastic deformation [3]. Obviously, the deformation behavior of TA2 is sensitive to the processing parameters, such as the strain rate, strain and deformation temperature. Thus, it is quite important to analyze its deformation behavior. Because of the development of numerical simulation method, finite element method (FEM) has been applied successfully and widely into the analysis of the optimization of hot processing parameters and the metal forming processes $[4,5]$. The material flow behavior can be represented through the constitutive equation, which is input into FEM to trigger the deformation behavior of the material in certain loading conditions [6-8]. Thus, the accuracy of simulation results relies intensively over the accuracy of the constitutive equation.

There are massive constitutive models being proposed to illustrate the flow behavior in hot working, such as the physically based, phenomenological, semiempirical and empirical models [9-14]. In general, an ideal constitutive equation is supposed to involve massive material constants, which can be assessed from limited experimental data and should be capable 
to illustrate the flow behavior with great accuracy over a processing range [15]. The Johnson-Cook (JC) model has been widely employed in different commercial FEMs among these models to illustrate the high-temperature deformation behavior of alloys with its rapid calculation speed, small calculation quantity and simple form [16]. It is decided by five major material constants. However, such constitutive model overlooks the combined effect of the influential factors over the flow stress, which can reduce the accuracy of the constitutive equation [17]. Afterward, there is an improved JC model being proposed by Lin et al. [18] to deal with the inadequacies of the original JC model. It has been later successfully used for the estimation of the flow stress. The Zerilli-Armstrong (ZA) model serves as a part of the commercial FEM software, considering the temperature effects and coupled strain effects. Besides, according to the report, the modified ZA model can be applied to estimate the elevated temperature flow behavior on a variety of strains, temperatures and strain rates [19]. Hongyi Zhan et al. [20] proposed the modified ZA model to estimate the flow behavior of Ti-6Cr-5Mo-5V-4Al alloy in $\beta$-phase over a wide range of high strain rates and temperatures. At the same time, the hyperbolic sine Arrheniustype constitutive model being proposed by Mc Tegart and Sellars [21] has been employed successfully to assess the elevated temperature flow behavior of materials. Great effort has been made to revise such equation. Afterward, the strain-compensated parameters were used to estimate the flow stress of metallic materials, such as GH4169 [22], 42CrMo steel [23] and Inconel 718 superalloy [24].

This research aims to generate suitable constitutive questions according to strain-compensated Arrheniustype model, the modified ZA model, the modified JC model and the JC model to estimate the evaluated temperature flow stress of TA2 in $\alpha$-phase region. Afterward, a comparative research over the capacity to estimate the elevated temperature flow behavior has been made. For this purpose, isothermal hot compression tests were made under the temperature range of $933-1,133 \mathrm{~K}$ and a wide range of strain rates ranging $0.1-20 \mathrm{~s}^{-1}$. Afterward, the experimental stress-strain data were employed to derive the strain-compensated Arrheniustype model, the modified ZA model, the modified JC model and the JC model. At last, the suitability of these three models was assessed through the comparison of the correlation coefficient $(R)$ and the average absolute relative error (AARE).

\section{Experimental procedures}

The as-received material is a hot-rolled titanium plate with Grade-2. The chemical composition (mass \%) of TA2 investigated in the present study is given in Table 1.

Table 1: Chemical composition of as-received TA2 billet.

\begin{tabular}{llllllll}
\hline Main component (mass \%) & & \multicolumn{5}{c}{ Impurities (mass \%) } \\
\cline { 1 - 5 } \cline { 5 - 8 } & & Fe & C & N & H & O \\
\hline Balance & & 0.03 & 0.08 & 0.03 & 0.015 & 0.25 \\
\hline
\end{tabular}

The hot compression tests mainly adopted the cylindrical specimens with a height of $12 \mathrm{~mm}$ and a diameter of $8 \mathrm{~mm}$. Afterward, they were cut from the plate along the rolling direction, which is illustrated in Figure 1. Hot compression was made over a Gleeble-3500 thermal simulator. Before the hot compression, every specimen was warmed up to the deformation temperature under the rate of $5 \mathrm{~K} \cdot \mathrm{s}^{-1}$, and held for $5 \mathrm{~min}$ at the isothermal conditions and hence to guarantee a homogenous temperature distribution of the specimen. A thermal couple spot was welded to the center region of the specimen surface under the deformation temperature. The graphite foil was imposed between the specimen and the anvil and hence to decrease the friction and avoid sticking. Compression tests were made from 933 to $1,133 \mathrm{~K}$ with $50 \mathrm{~K}$ intervals varying the strain rates from 0.1 to $20 \mathrm{~s}^{-1}$. The samples were deformed later to a true compression strain of 1.2. Afterward, it was quenched in water immediately to keep the deformed microstructures while the stress-strain curves were automatically recorded in the isothermal compression process through the Gleeble-3500 thermal simulator system. Figure 2 presents the deformation process.

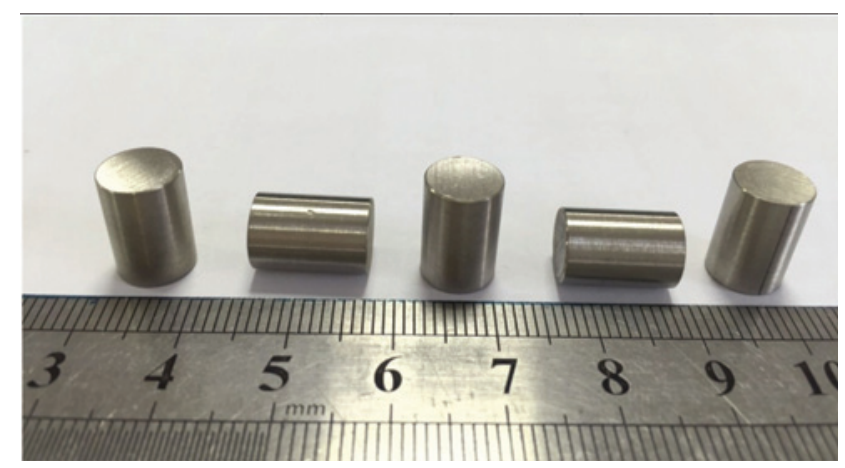

Figure 1: Typical appearance of the TA2 specimens. 


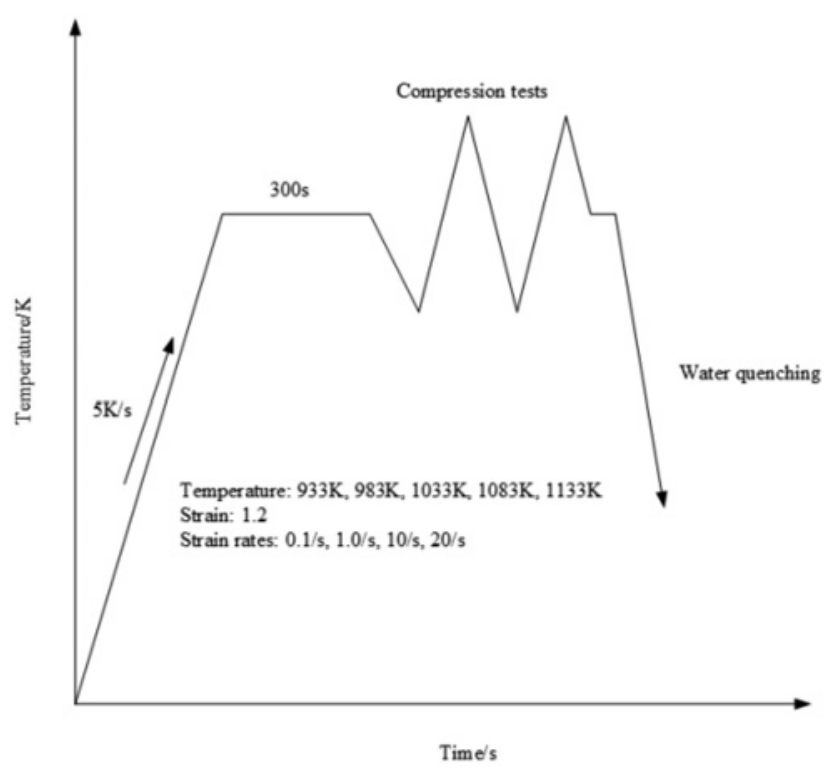

Figure 2: Thermomechanical schedule of the compression tests.

\section{Result and discussion}

\section{Johnson-Cook model}

The basic form of the JC model is expressed as following [20]:

$$
\sigma=\left(A+B \varepsilon^{n}\right)\left(1+C \ln \varepsilon^{\star}\right)\left(1-T^{\star} m\right)
$$

where $\sigma$ is flow stress in $\mathrm{MPa}, \varepsilon$ is the true strain, $\varepsilon^{\star}=\varepsilon / \varepsilon_{0}$ is the dimensionless strain rate with $\dot{\varepsilon}$ being the strain rate $\left(\mathrm{s}^{-1}\right)$ and $\varepsilon_{0}$ the reference strain rate $\left(\mathrm{s}^{-1}\right), A$ is the yield stress at reference temperature and strain rate, $B$ is the coefficient of strain hardening, $n$ is the exponent of strain hardening and $T^{*}$ is homologous temperature and expressed as eq. (2):

$$
T^{\star}=\frac{T-T_{r e f}}{T_{m}-T_{r e f}}
$$

where $T$ is the current and reference temperatures (K), $T_{m}$ is the melting temperature $\left(1,941 \mathrm{~K}\right.$ for TA2) and $T_{r e f}$ is the reference temperature $\left(T \geq T_{r e f}\right) . C$ and $m$ are the material constants that represent the coefficient of strain rate hardening and thermal softening exponent, respectively.

Based on the current study, $1 \mathrm{~s}^{-1}$ and $933 \mathrm{~K}$ have been set as the reference strain rate and reference temperature, respectively. When the strain rate is $1 \mathrm{~s}^{-1}$ and the deformation temperature is $933 \mathrm{~K}$, eq. (1) can be expressed as

$$
\sigma=\left(A+B \varepsilon^{n}\right)
$$

The value of $A$ is generated from the yield stress of the flow curve at $933 \mathrm{~K}$ as well as $1 \mathrm{~s}^{-1}$ (97.793 MPa). When the value of $A$ is substituted into eq. (3), the relationship between $\ln \varepsilon$ and $\ln (\sigma-A)$ can be generated. Figure 3 demonstrates the relationship between $\ln \varepsilon$ at $933 \mathrm{~K}$ and $\ln (\sigma-A)$ and $\ln \varepsilon$ at $933 \mathrm{~K}$ and $1 \mathrm{~s}^{-1}$. Then, the values of $B$ and $n$ can be obtained from the fitting curve.

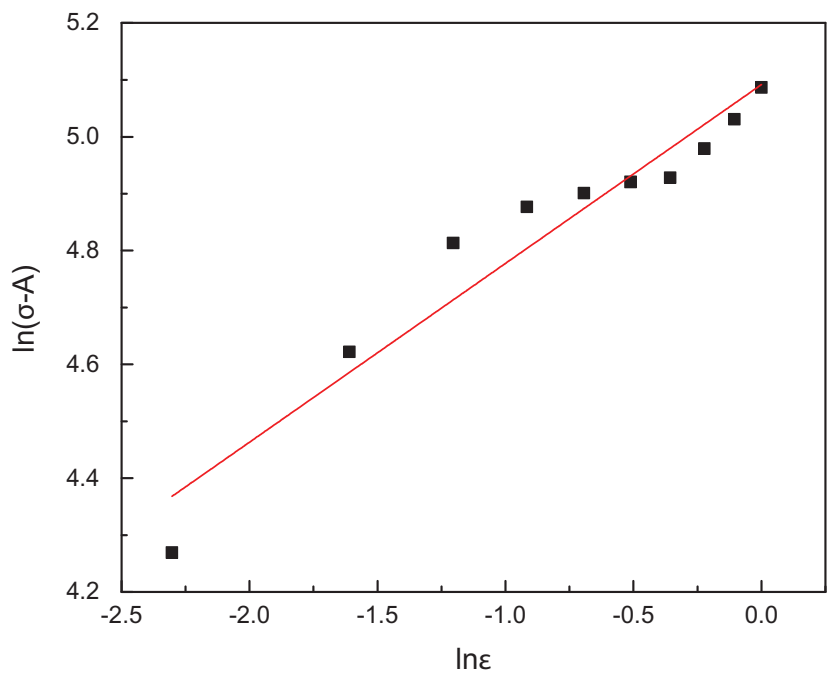

Figure 3: Relationship between $\ln (\sigma-A)$ and $\ln \varepsilon$ at $933 \mathrm{~K}$ and $1 \mathrm{~s}^{-1}$.

Eq. (1) can be expressed as follows when the deformation temperature is $933 \mathrm{~K}$ :

$$
\sigma=\left(A+B \varepsilon^{n}\right)\left(1+C \ln \dot{\varepsilon}^{\star}\right)
$$

The slope of lines in lines in $\sigma /\left(A+B \varepsilon^{n}\right)-\ln \dot{\varepsilon}^{\star}$ plot can be used to obtain the values of $C$. Figure 4 presents the variation of $\sigma /\left(A+B \varepsilon^{n}\right)$ with $\ln \dot{\varepsilon}^{*}$ at the temperature of $933 \mathrm{~K}$.

By the same token, the flow stress and the thermal softening term were independent from each other at the reference strain rate $1 \mathrm{~s}^{-1}$ since $\ln \dot{\varepsilon}^{\star}=0$. Thus, eq. (1) can be expressed as:

$$
\sigma=\left(A+B \varepsilon^{n}\right)\left(1-T^{\star} m\right)
$$




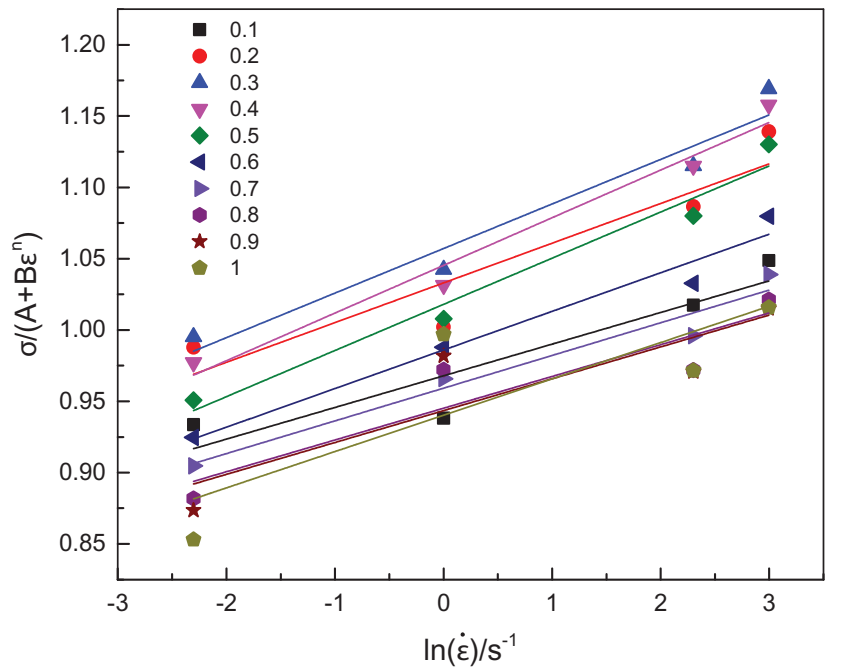

Figure 4: Relationship between $\left(\sigma /\left(A+B \varepsilon^{n}\right)\right)$ and $\ln \dot{\varepsilon}^{*}$ at the temperature of $933 \mathrm{~K}$.

The relationship between $\ln T^{\star}$ and $\ln \left[1-\sigma /\left(A+B \varepsilon^{n}\right)\right]$ can be generated at different temperatures for a specific strain. Afterward, the values of $m$ for these eight different strains can be generated through the slopes of the linear fitting curves, which is demonstrated in Figure 5.

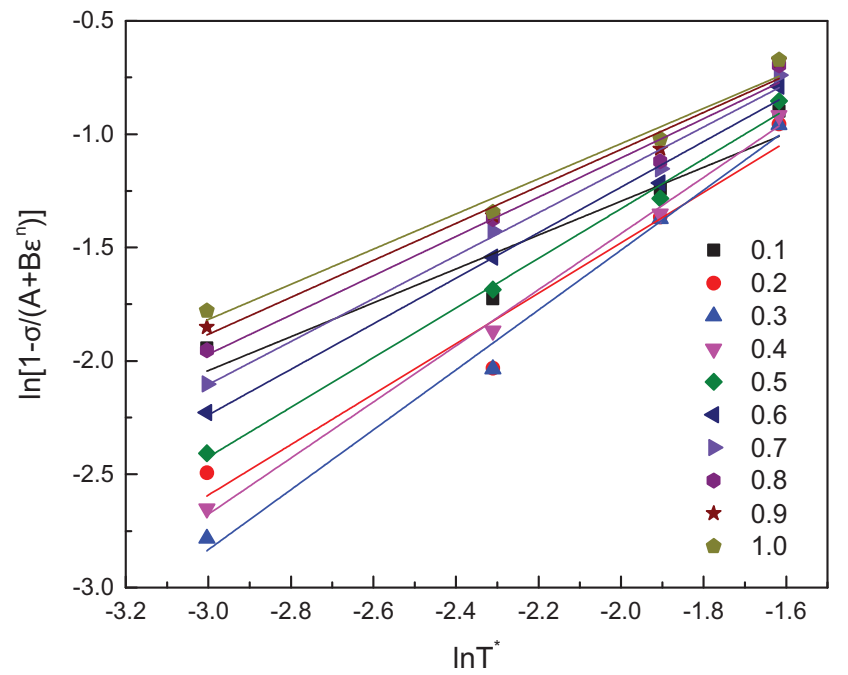

Figure 5: Relationship between $\ln \left[1-\sigma /\left(A+B \varepsilon^{n}\right)\right]$ and $\ln T^{*}$.

The material constants of the JC model for TA2 are provided in Table 2.

Then, the JC constitutive equation for TA2 can be obtained:
Table 2: Parameters for the Johnson-Cook model.

\begin{tabular}{|c|c|c|c|c|c|}
\hline Parameter & $A$ & B & $n$ & $C$ & $m$ \\
\hline Value & 97.793 & 162.663 & 0.294 & 0.0267 & 0.992 \\
\hline
\end{tabular}

Using the constitutive equation above, the flow stress data for TA2 are predicted at various processing conditions. Comparisons between the experimental and predicted data at various processing conditions using eq. (6) are shown in Figure 6.

Based on Figure 6, it can be seen that there is a dramatic deviation of the predicted flow stresses in the majority of the deformation conditions. Only under the temperature of $933 \mathrm{~K}$ and the strain rate of $1.0 \mathrm{~s}^{-1}$, the predicted flow stress data could be consistent with the experimental flow stress data of TA2. Afterward, when there is an increase of the temperature, the deviation will get larger compared with the experimental value. The flow stress reduces corresponding with the decrease of the strain rates and the increase of the temperature.

\section{Modified Johnson-Cook model}

The modified JC model is expressed as follows:

$$
\begin{aligned}
\sigma= & \left(A_{1}+B_{1} \varepsilon+B_{2} \varepsilon^{2}+B_{3} \varepsilon^{3}\right)\left(1+C_{1} \ln \dot{\varepsilon}^{\star}+C_{2} \ln \dot{\varepsilon}^{\star 2}+C_{3} \ln \dot{\varepsilon}^{* 3}\right) \\
& \exp \left[\left(\lambda_{1}+\lambda_{2} \ln \dot{\varepsilon}^{\star}+\lambda_{3} \ln \dot{\varepsilon}^{\star 2}+\lambda_{4} \ln \dot{\varepsilon}^{\star 3}\right) T^{*}\right]
\end{aligned}
$$

where $\sigma$ refers to the stress in $\mathrm{MPa}, \varepsilon$ is the true strain, $\varepsilon^{\star}=\varepsilon / \varepsilon_{0}$ is the dimensionless strain rate with $\dot{\varepsilon}$ being the strain rate $\left(\mathrm{s}^{-1}\right)$ and $\varepsilon_{0}$ the reference strain rate $\left(\mathrm{s}^{-1}\right), A_{1}$, $B_{1}, B_{2}, B_{3}, C_{1}, C_{2}, C_{3}, \lambda_{1}, \lambda_{2}, \lambda_{3}, \lambda_{4}$ are the material constants. $T^{*}$ can be expressed as eq. (8):

$$
T^{\star}=T-T_{\text {ref }}
$$

where $T_{r e f}$ is the reference temperature.

According to the current study, $1 \mathrm{~s}^{-1}$ and $933 \mathrm{~K}$ have been set as the reference strain rate and reference temperature, respectively. When the strain rate is $1 \mathrm{~s}^{-1}$ and the deformation temperature is $933 \mathrm{~K}$, then eq. (7) can be expressed as: 


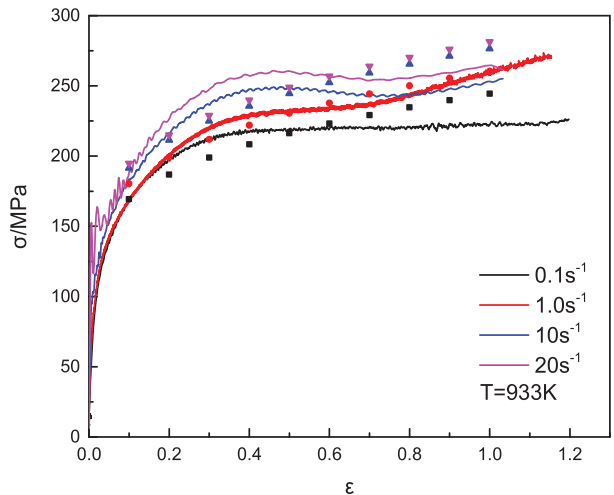

(a)

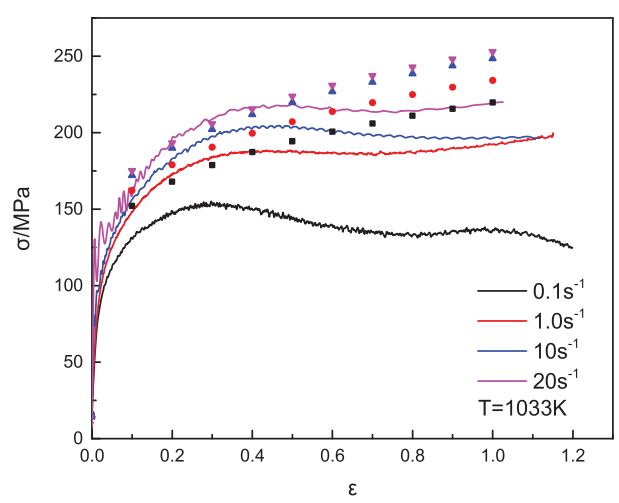

(c)

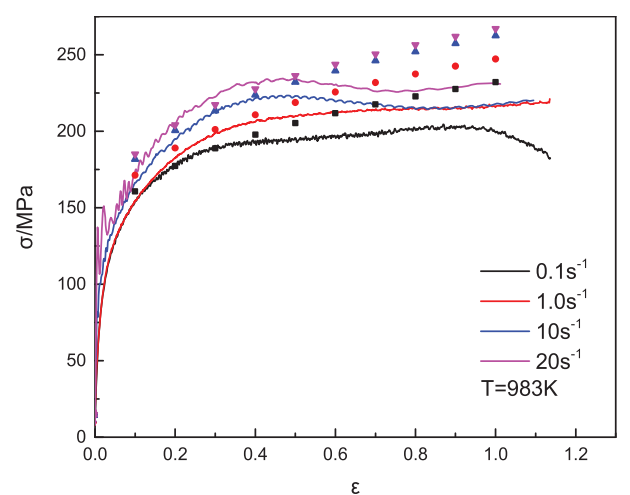

(b)

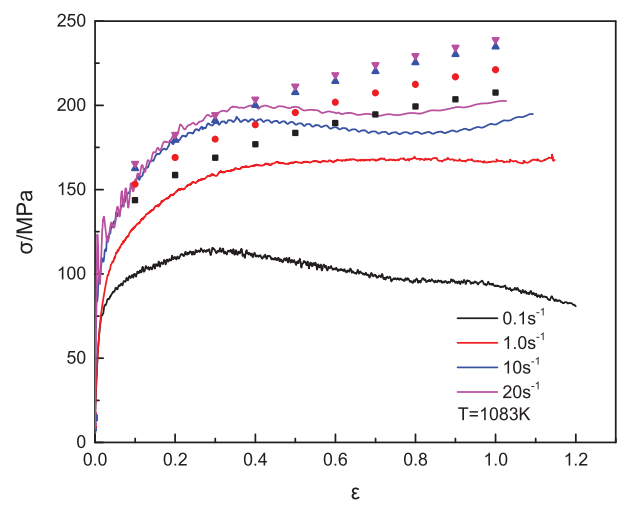

(d)

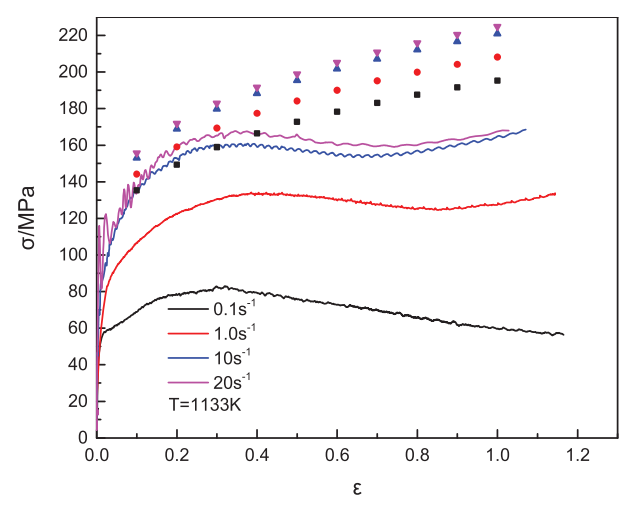

(e)

Figure 6: Comparison between experimental and predicted flow stress using Johnson-Cook model at the temperatures of (a) $933 \mathrm{~K}$, (b) $983 \mathrm{~K}$, (c) $1,033 \mathrm{~K}$, (d) $1,083 \mathrm{~K}$, (e) $1,133 \mathrm{~K}$.

$$
\sigma=A_{1}+B_{1} \varepsilon+B_{2} \varepsilon^{2}+B_{3} \varepsilon^{3}
$$

The corresponding experimental flow stress data have been substituted into eq. (9) while the relationship between $\varepsilon$ and $\sigma$ can be obtained. Then, the values of $A_{1}, B_{1}, B_{2}$ and $B_{3}$ can be obtained from the fitting curves of Figure 7.

When the deformation temperature is reference temperature, eq. (7) can be expressed as:

The values of $C_{1}, C_{2}, C_{3}$ can be obtained from the $\sigma /\left(A_{1}+\right.$ $\left.B_{1} \varepsilon+B_{2} \varepsilon^{2}+B_{3} \varepsilon^{3}\right)-\ln \dot{\varepsilon}^{*}$ plot. Figure 8 shows the variation of $\sigma /\left(A_{1}+B_{1} \varepsilon+B_{2} \varepsilon^{2}+B_{3} \varepsilon^{3}\right)$ with $\ln \dot{\varepsilon}^{*}$ at the temperature of $933 \mathrm{~K}$.

Then, introducing one new parameter $\lambda$, which is expressed as: 


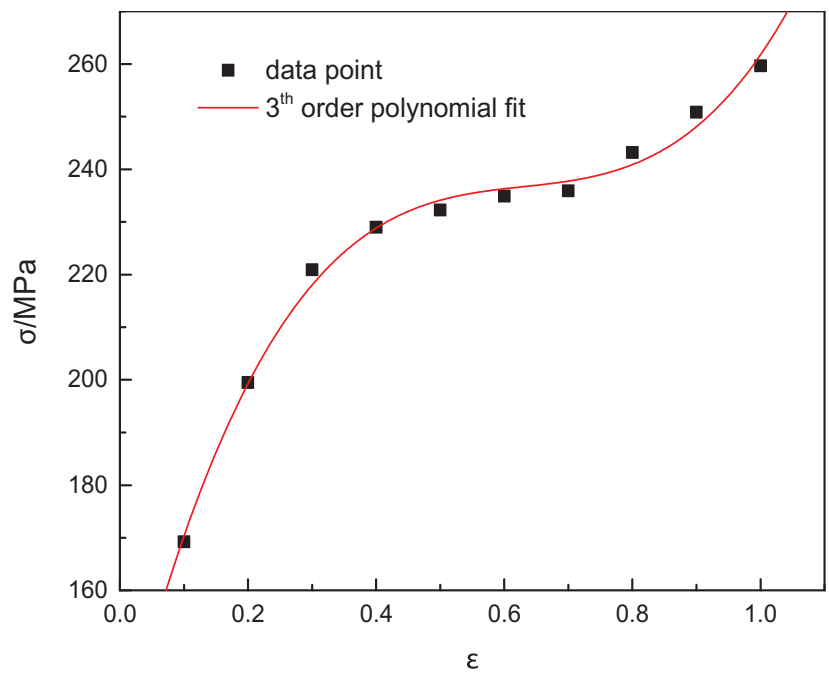

Figure 7: Relationship between $\sigma$ and $\varepsilon$ at $933 \mathrm{~K}$ and $1 \mathrm{~s}^{-1}$.

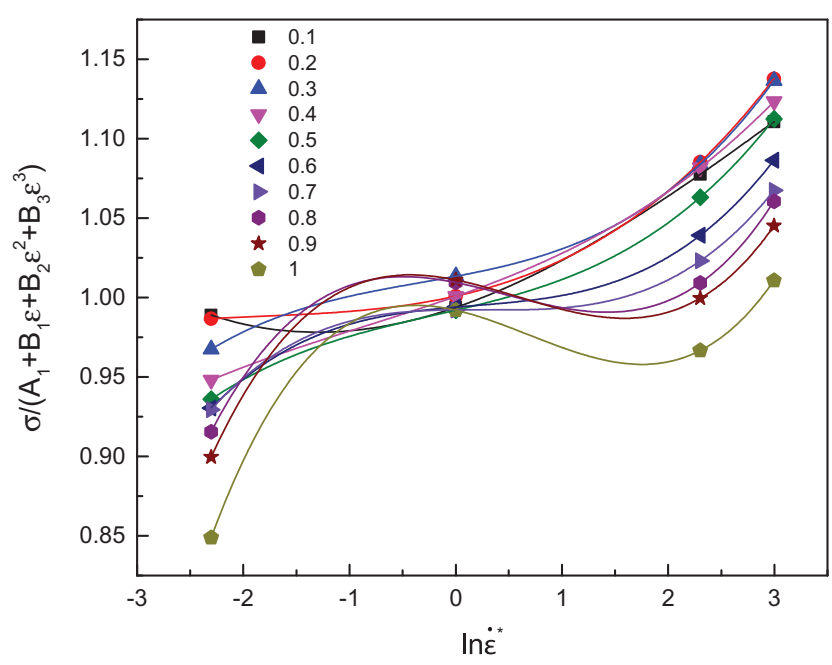

Figure 8: Relationship between $\sigma /\left(A_{1}+B_{1} \varepsilon+B_{2} \varepsilon^{2}+B_{3} \varepsilon^{3}\right)$ and $\ln \dot{\varepsilon}^{*}$ at the temperature of $933 \mathrm{~K}$.

$$
\lambda=\lambda_{1}+\lambda_{2} \ln \dot{\varepsilon}^{\star}+\lambda_{3} \ln \dot{\varepsilon}^{\star 2}+\lambda_{4} \ln \dot{\varepsilon}^{\star 3}
$$

Eq. (7) can be written as follows:

$$
\frac{\sigma}{\left(A_{1}+B_{1} \varepsilon+B_{2} \varepsilon^{2}+B_{3} \varepsilon^{3}\right)\left(1+C_{1} \ln \dot{\varepsilon}^{\star}+C_{2} \ln \dot{\varepsilon}^{\star 2}+C_{3} \ln \dot{\varepsilon}^{* 3}\right)}=e^{\lambda T^{*}}
$$

Taking the logarithm of both sides of eq. (12), it generates:

$$
\begin{aligned}
& \ln \left[\frac{\sigma}{\left(A_{1}+B_{1} \varepsilon+B_{2} \varepsilon^{2}+B_{3} \varepsilon^{3}\right)\left(1+C_{1} \ln \dot{\varepsilon}^{*}+C_{2} \ln \dot{\varepsilon}^{* 2}+C_{3} \ln \dot{\varepsilon}^{* 3}\right)}\right] \\
& =\lambda T^{\star}
\end{aligned}
$$

The values of $\lambda$ are obtained based on the mean values of $\ln \left[\frac{\sigma}{\left(A_{1}+B_{1} \varepsilon+B_{2} \varepsilon^{2}+B_{3} \varepsilon^{3}\right)\left(1+C_{1} \ln \dot{\varepsilon}^{*}+C_{2} \ln \dot{\varepsilon}^{* 2}+C_{3} \ln \dot{\varepsilon}^{* 3}\right)}\right] \quad$ at different strains (0.1-1.0). The relationship between $\ln$ $\left[\frac{\sigma}{\left(A_{1}+B_{1} \varepsilon+B_{2} \varepsilon^{2}+B_{3} \varepsilon^{3}\right)\left(1+C_{1} \ln \varepsilon^{*}+C_{2} \ln \varepsilon^{* 2}+C_{3} \ln \varepsilon^{* * 3}\right)}\right]$ and $T^{\star}$ can also be obtained for different strain rates and deformation temperatures. Then, the values of $\lambda$ for four different strain rates can be obtained based on the slopes of the linear fitting curves.

Based on eq. (11), the value of $\lambda_{1}, \lambda_{2}, \lambda_{3}, \lambda_{4}$ can be obtained from the $\lambda-\ln \dot{\varepsilon}^{*}$ plot. Figure 9 demonstrates the relationship between $\ln \dot{\varepsilon}^{\star}$ and $\lambda$.

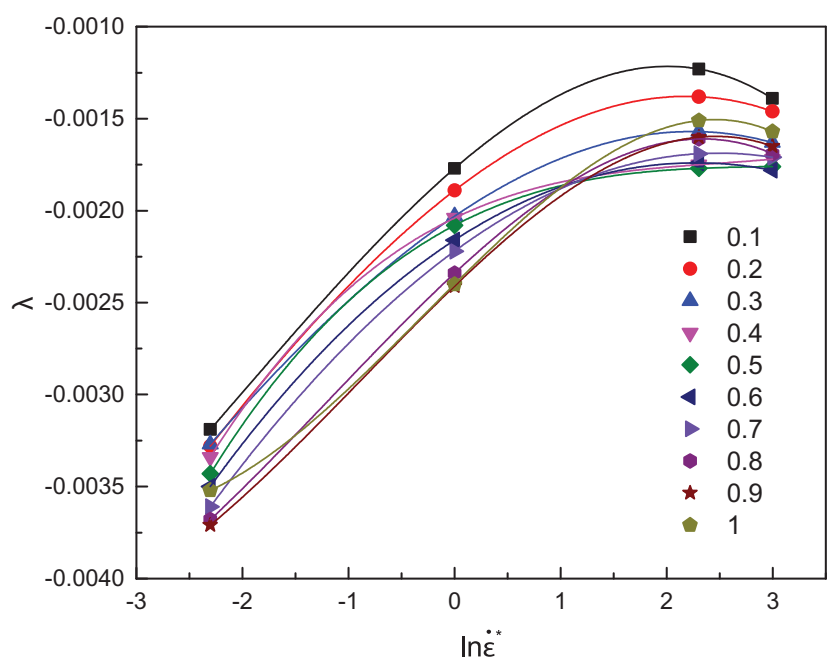

Figure 9: Relationship between $\lambda$ and $\ln \dot{\varepsilon}^{*}$.

Table 3 presents the parameters of the modified JC model for TA2.

The modified JC constitutive equation can be generated, which is listed below:

$$
\begin{aligned}
\sigma= & \left(128.63+488.34 \varepsilon-754.22 \varepsilon^{2}+399.00 \varepsilon^{3}\right) \\
& \left(1+0.00534 \ln \dot{\varepsilon}^{\star}-0.0021 \ln \dot{\varepsilon}^{\star 2}+0.0034 \ln \dot{\varepsilon}^{\star 3}\right) \\
& \exp \left[\left(-0.002134+0.00044 \ln \dot{\varepsilon}^{*}-7.26 \times 10^{-5} \ln \dot{\varepsilon}^{\star 2}\right.\right. \\
& \left.\left.-5.95 \times 10^{-6} \ln \dot{\varepsilon}^{\star 3}\right) T^{\star}\right]
\end{aligned}
$$

The constitutive equation listed above is obtained while the stress data for TA2 is estimated under different processing conditions. Comparisons between the predicted data and experimental data at different processing conditions are made based on eq. (14), which is listed in Figure 10. 
Table 3: Parameters for the modified Johnson-Cook model.

\begin{tabular}{|c|c|c|c|c|c|c|c|c|c|c|c|}
\hline Parameter & $A_{1}$ & $B_{1}$ & $B_{2}$ & $B_{3}$ & $c_{1}$ & $C_{2}$ & $C_{3}$ & $\lambda_{1}$ & $\lambda_{2}$ & $\lambda_{3}$ & $\lambda_{4}$ \\
\hline Value & 128.63 & 488.34 & -754.22 & 399.00 & 0.00534 & -0.0021 & 0.0034 & -0.002134 & 0.00044 & $-7.26 \times 10^{-5}$ & $-5.95 \times 10^{-6}$ \\
\hline
\end{tabular}

Based on Figure 10, it can be observed that there is a good agreement shown in the predicted flow stresses in the lower temperature of 983 and $933 \mathrm{~K}$. There is a deviation of the higher temperature. The strain rates decrease corresponding with the increase in the temperature. The deviation is larger compared with the experimental value. However, it is better than that of JC model.

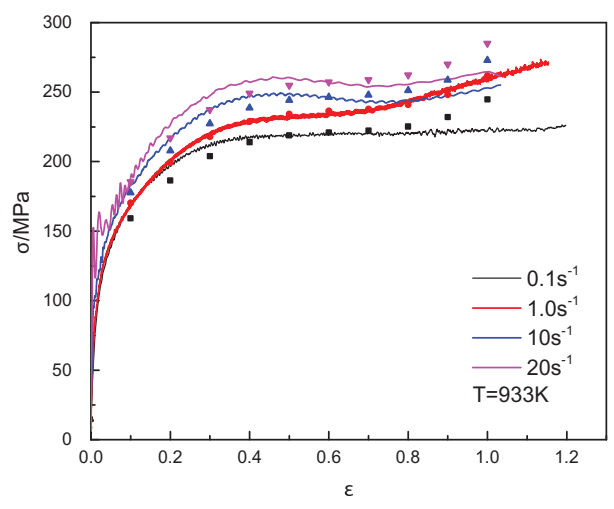

(a)

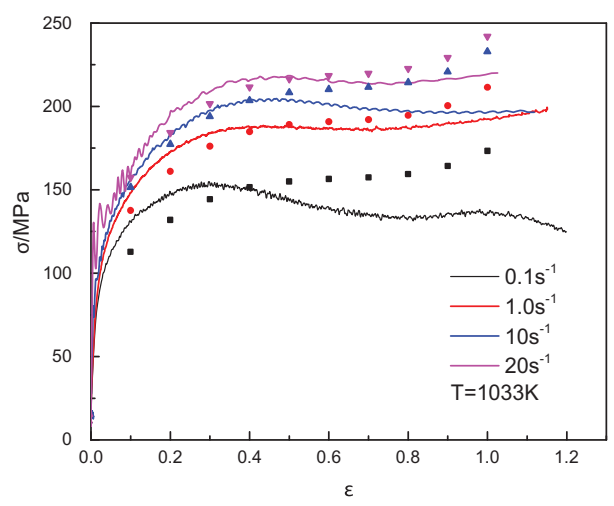

(c)

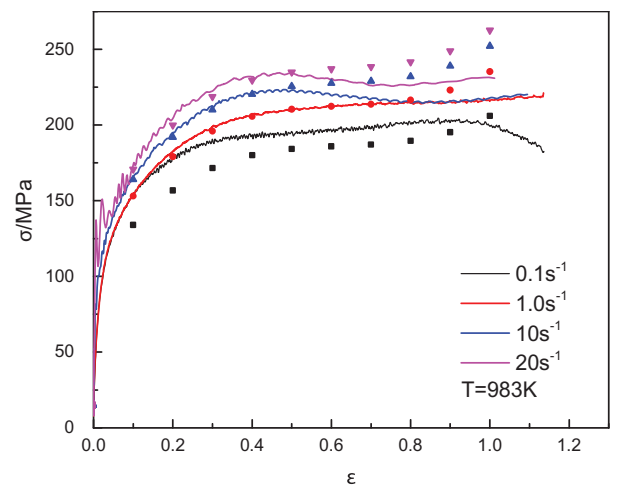

(b)

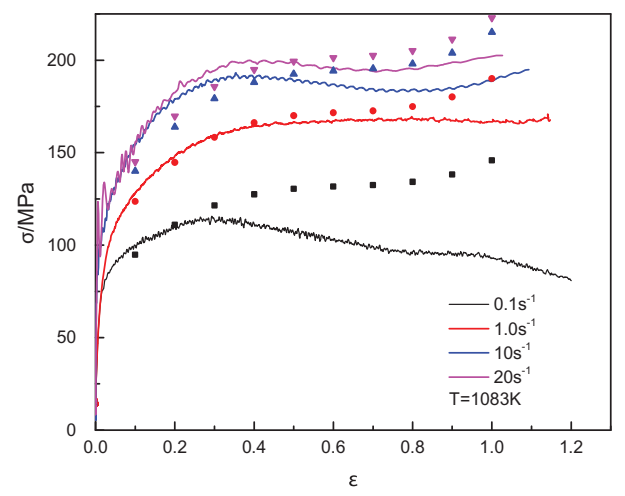

(d)

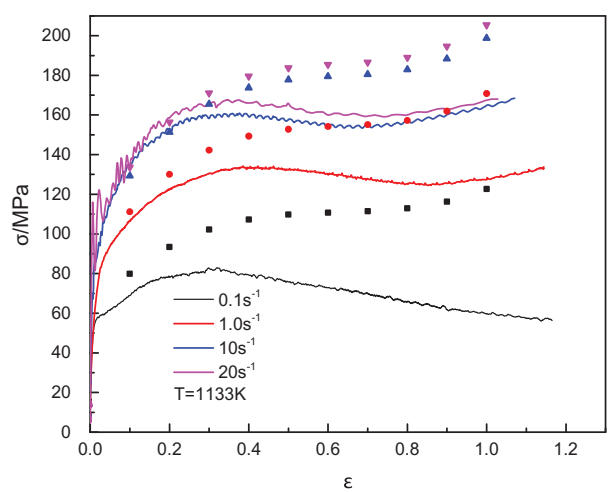

(e)

Figure 10: Comparison between experimental and predicted flow stress using Johnson-Cook model at the temperatures of (a) $933 \mathrm{~K}$, (b) $983 \mathrm{~K}$, (c) $1,033 \mathrm{~K}$, (d) $1,083 \mathrm{~K}$, (e) $1,133 \mathrm{~K}$. 


\section{Modified ZA model}

The modified ZA constitutive model has been applied to estimate the flow stress behavior of the materials under high temperatures, which are listed as following [19].

$$
\sigma=\left(C_{1}+C_{2} \varepsilon^{n}\right) \exp \left[-\left(C_{3}+C_{4} \varepsilon\right) T^{\star}+\left(C_{5}+C_{6} T^{\star}\right) \ln \dot{\varepsilon}^{\star}\right]
$$

where $\dot{\varepsilon}^{\star}=\dot{\varepsilon} / \varepsilon_{0}$ refers to the dimensionless strain rate with $\dot{\varepsilon}$ being the strain rate $\left(\mathrm{s}^{-1}\right)$ and $\varepsilon_{0}$ the reference strain rate $\left(\mathrm{s}^{-1}\right), T^{\star}=T-T_{\text {ref }}$ and $T_{\text {ref }}$ are the current and reference temperatures (K), respectively. $C_{1}, C_{2}, C_{3}, C_{4}, C_{5}$, $C_{6}$ and $n$ are the materials constants. According to the current study, $1 \mathrm{~s}^{-1}$ and $933 \mathrm{~K}$ are the reference strain rate and reference temperature, respectively. In addition, the relative procedures of the evaluation of the material constants are illustrated below:

According to eq. (15), the following expression could be obtained at $\dot{\varepsilon}^{\star}=1$.

$$
\sigma=\left(C_{1}+C_{2} \varepsilon^{n}\right) \exp \left[-\left(C_{3}+C_{4} \varepsilon\right) T^{\star}\right]
$$

Then taking natural logarithms on both sides of the formula, eq. (16) could be expressed as follows:

$$
\ln \sigma=\ln \left(C_{1}+C_{2} \varepsilon^{n}\right)-\left(C_{3}+C_{4} \varepsilon\right) T^{\star}
$$

The correlation between $\ln \sigma$ and $T^{\star}$ can be obtained (shown in Figure 11). Afterward, the values of $-\left(C_{3}+C_{4} \varepsilon\right)$ and the

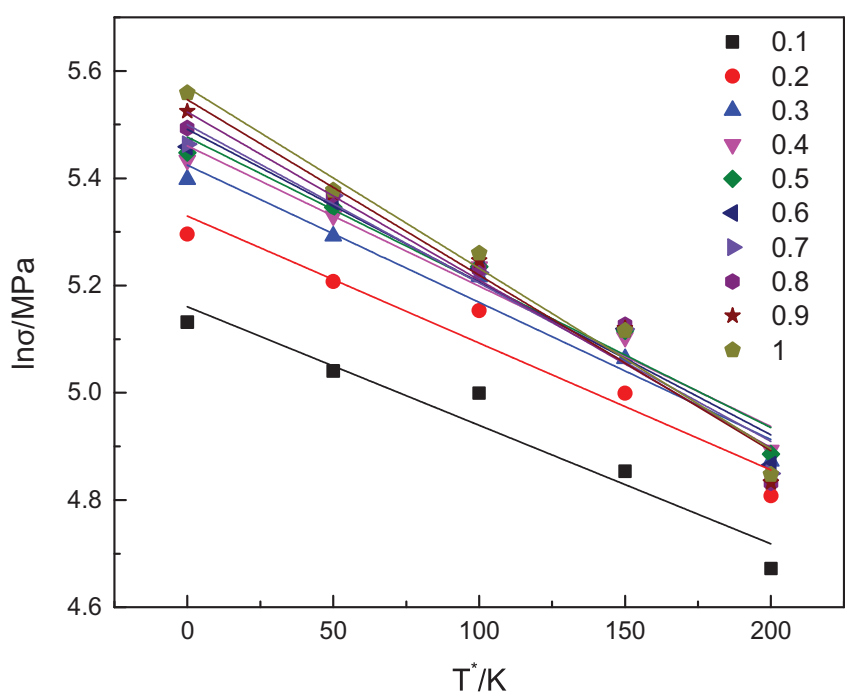

Figure 11: The relationship between $\ln \sigma$ and $T^{\star}$ at the reference strain rate. values of $\ln \left(C_{1}+C_{2} \varepsilon^{n}\right)$ can be obtained from the intercept $l_{1}$ and slope $S_{1}$ of the line in the plot, respectively. Then,

$$
l_{1}=\ln \left(C_{1}+C_{2} \varepsilon^{n}\right)
$$

And eq. (18) can be transformed as following:

$$
\ln \left(\operatorname{expl}_{1}-C_{1}\right)=\ln C_{2}+n \ln \varepsilon
$$

$C_{1}$ is determined based on the yield stress of the stress-strain curve at $T=933 \mathrm{~K}$ and $\dot{\varepsilon}^{\star}=1$. Substituting $C_{1}$ in eq. (18) and plotting the $\ln \left(\operatorname{expl}_{1}-C_{1}\right)$ and $\ln \varepsilon$ graph, the $C_{2}$ and $n$ can be calculated, as shown in Figure 12. Similarly, the slope of the line represented by eq. (19) can be written as

$$
S_{1}=-\left(C_{3}+C_{4} \varepsilon\right)
$$

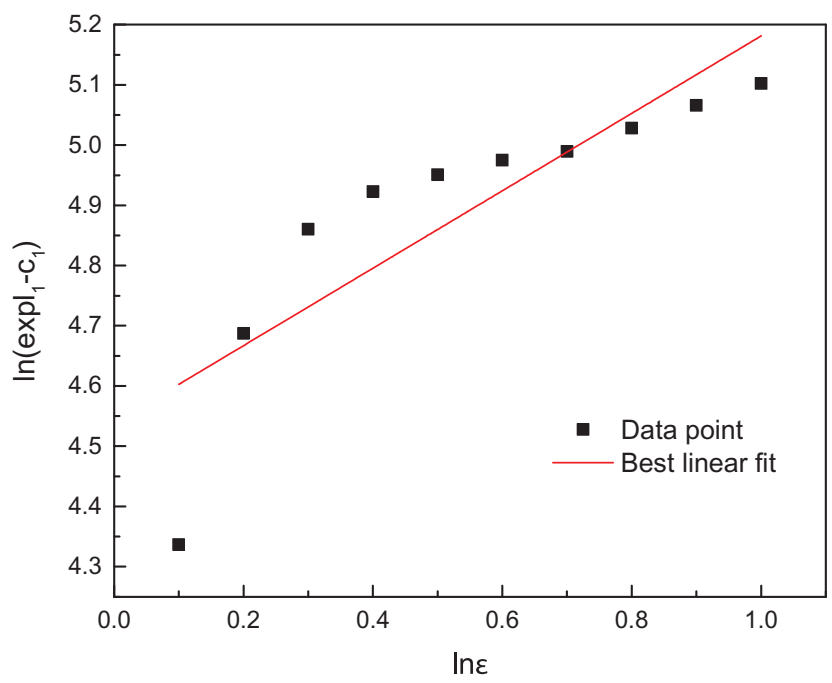

Figure 12: Relationship between $\ln \left(\exp l_{1}-C_{1}\right)$ and $\ln \varepsilon$.

Thus, $C_{3}$ and $C_{4}$ can be generated easily based on the slope and intercept of the plot of $S_{1}$ and $\varepsilon$, respectively, which is shown in Figure 13. The natural logarithms of both sides of eq. (15) have been applied, which derives the following expression.

$$
\ln \sigma=\ln \left(C_{1}+C_{2} \varepsilon^{n}\right)-\left(C_{3}+C_{4} \varepsilon\right) T^{\star}+\left(C_{5}+C_{6} T^{\star}\right) \ln \dot{\varepsilon}^{\star}
$$

As it can be seen from eq. (21), the slope $S_{2}$ of the $\ln \sigma-\ln \dot{\varepsilon}^{\star}$ curve plot is the value of $\left(C_{5}+C_{6} T^{\star}\right)$. Therefore, a group of slope values under ten different strains and five different temperatures were generated. There are five different values of $S_{2}$ which can be obtained under specific strain while the slope $S_{2}$ can be expressed as: 


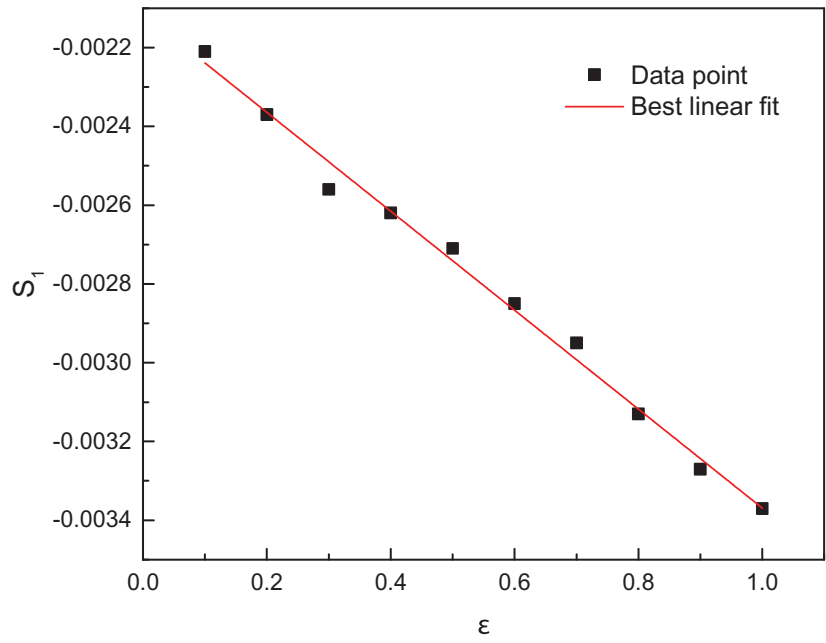

Figure 13: Relationship between $S_{1}$ and $\varepsilon$.

$$
S_{2}=C_{5}+C_{6} T^{\star}
$$

Thus, $C_{5}$ and $C_{6}$ can be generated easily from the slope and intercept of the plot of $S_{2}$ and $T^{\star}$, which can be observed from Figure 14.

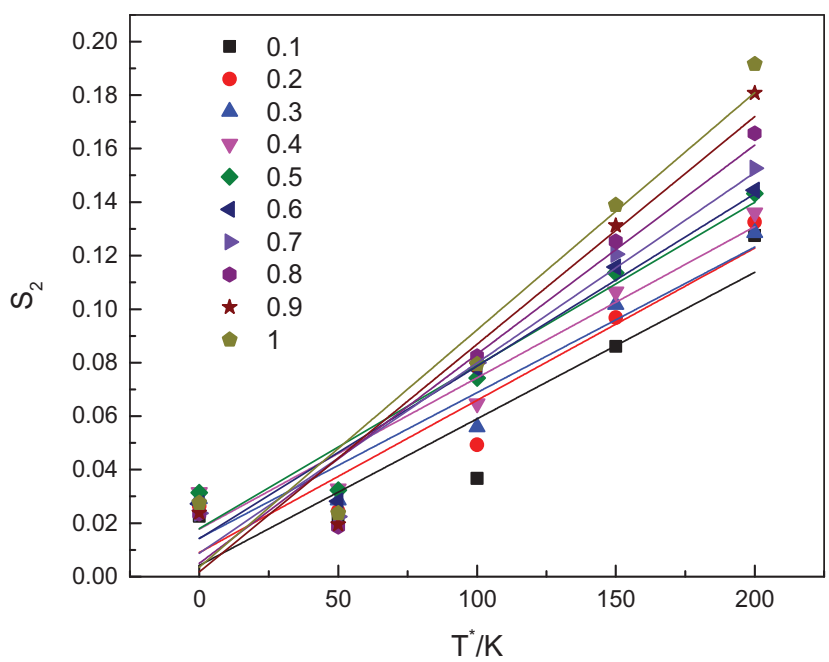

Figure 14: Relationship between $S_{2}$ and $T^{*}$ at different strains.

Therefore, all of the constants of the modified ZA model could be obtained as shown in Table 4 .
Then the modified ZA model for TA2 can be obtained:

$$
\begin{aligned}
\sigma= & \left(97.793+93.541 \varepsilon^{0.643}\right) \exp \left[-(0.00211+0.00126 \varepsilon) T^{\star}\right. \\
& \left.+\left(0.00962+0.000671 T^{\star}\right) \ln \dot{\varepsilon}^{\star}\right]
\end{aligned}
$$

The constitutive equation above is used to estimate the flow stress data for different deformation conditions. Comparison between the predicted and experimental values by modified ZA model under different processing conditions is presented in Figure 15.

Based on Figure 15, it can be seen that there is a dramatic deviation of the deformation conditions of the predicted flow stresses. The reason why there is such phenomenon is might be that the ZA model is applied to analyze the body-centered cubic (BCC) materials and facecentered cubic (FCC) materials. However, according to this study, it is a kind of $\alpha$-phase hexagonal close-packed commercially pure titanium.

\section{Arrhenius-type model}

Arrhenius-type equation serves as a precise approach to illustrate the relationships between the deformation temperature, strain rate and flow stress. The common impact of the high temperature and strain rate over the hot deformation behavior can be shown through the exponent-type equation. It can be properly expressed through the ZenerHollomon parameter $(Z)$. These can be described using the following equations [25].

$$
\begin{gathered}
\mathrm{Z}=\dot{\operatorname{\varepsilon }} \exp \left(\frac{Q}{R T}\right) \\
\dot{\varepsilon}=A F(\sigma) \exp \left(-\frac{Q}{R T}\right) \\
\mathrm{F}(\sigma)=\left\{\begin{array}{cc}
\sigma^{n^{\prime}} & \alpha \sigma<0.8 \\
\exp (\beta \sigma) & \alpha \sigma>1.2 \\
{[\sinh (\alpha \sigma)]^{n}} & \text { for all } \sigma
\end{array}\right.
\end{gathered}
$$

where $R$ refers to the universal gas constant [8.314 $\mathrm{J} /(\mathrm{mol} \cdot \mathrm{K})], Q$ is the activation energy of hot deformation

Table 4: Parameters for the modified ZA model.

\begin{tabular}{lrrrrrrr}
\hline Parameter & $C_{1}$ & $C_{2}$ & $C_{3}$ & $C_{4}$ & $C_{5}$ & $C_{6}$ & $n$ \\
\hline Value & 97.793 & 93.541 & 0.00211 & 0.00126 & 0.00962 & 0.000671 & 0.643 \\
\hline
\end{tabular}




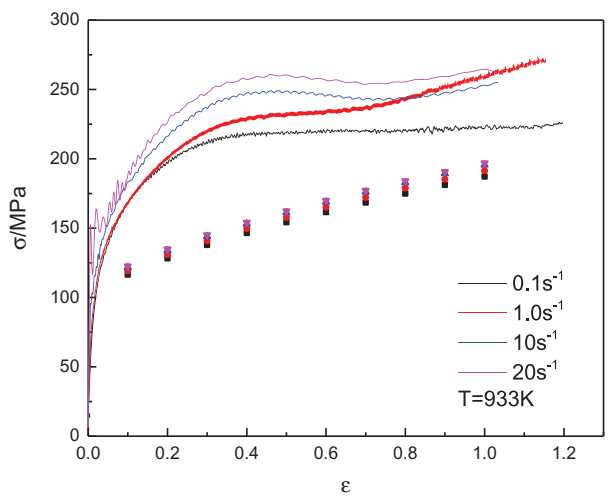

(a)

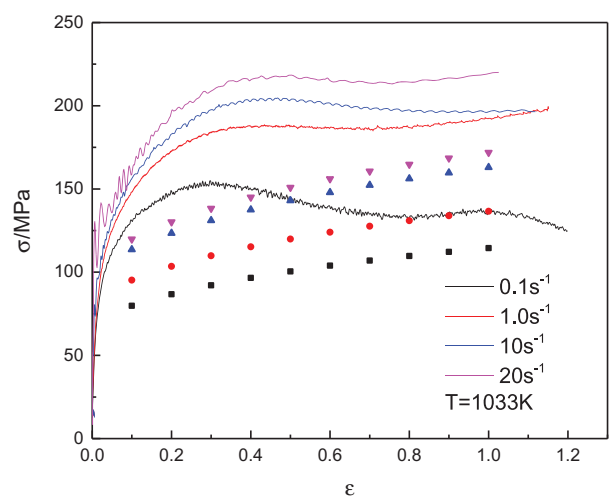

(c)

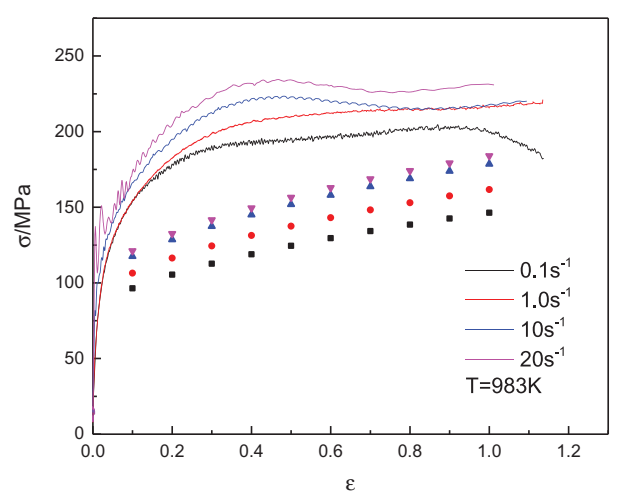

(b)

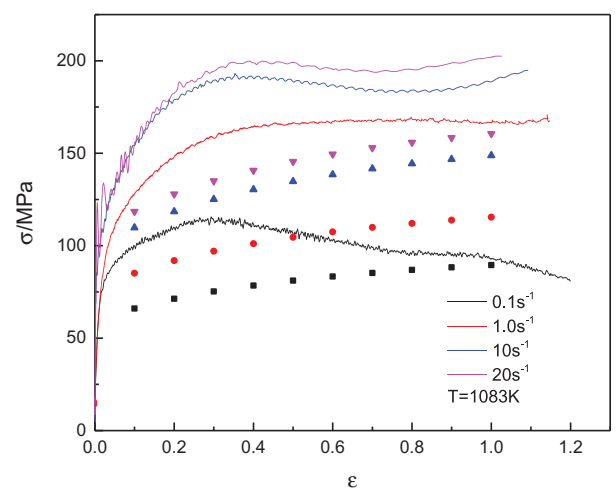

(d)

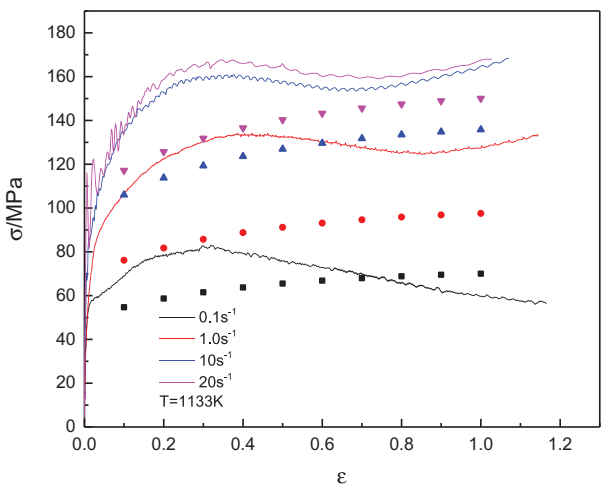

(e)

Figure 15: Comparison between experimental and predicted flow stress using modified ZA model at the temperatures of (a) $933 \mathrm{~K}$, (b) $983 \mathrm{~K}$, (c) $1,033 \mathrm{~K},(\mathrm{~d}) 1,083 \mathrm{~K}$, (e) 1,133 K.

(J/mol), $A, \mathrm{n}^{\prime}, \beta, \alpha$, and $n$ are the materials constants, and $\alpha=\beta / \mathrm{n}^{\prime}$.

The true stress-strain data from isothermal compression tests under different processing conditions is applied to decide the material constants of the Arrhenius-type constitutive model. The effect of the strain over the material constants is quite clear. It impacts the predictability of the constitutive model dramatically. However, the strain is not considered in eqs. (24) and (25). Therefore, the following research over the Arrhenius-type model is based on the compensation of the strain effect. The strain of 0.4 is taken as an example to describe the solution procedures for the material constants.

Under specific deformation temperature, the $F(\sigma)$ of eq. (26) under low stress level $(\alpha \sigma<0.8)$ and high stress level $(a \sigma>1.2)$ is substituted into eq. (25) in trun, the following relationships can be obtained, respectively.

$$
\dot{\varepsilon}=B \sigma^{n^{\prime}}
$$




$$
\dot{\varepsilon}=\operatorname{Cexp}(\beta \sigma)
$$

where $B$ and $C$ are the material constants.

Both sides of eqs. (27) and (28) are taken in the natural logarithms, and then they are transformed into a correlation function of $\sigma$, while the following equations can be obtained.

$$
\begin{gathered}
\ln (\sigma)=\frac{1}{n^{\prime}} \ln (\dot{\varepsilon})-\frac{1}{n^{\prime}} \ln (B) \\
\sigma=\frac{1}{\beta} \ln (\dot{\varepsilon})-\frac{1}{\beta} \ln (C)
\end{gathered}
$$

The values of the flow stress and corresponding strain rates under the strain of 0.4 are substituted into eq. (29) as well as eq. (30), respectively. The values of $\mathrm{n}^{\prime}$ and $\beta$ can be obtained from the slopes of the lines in the $\ln (\sigma)-\ln (\dot{\varepsilon})$ and $\sigma-\ln (\dot{\varepsilon})$ plots, respectively, as presented in Figure 16(a) and (b).

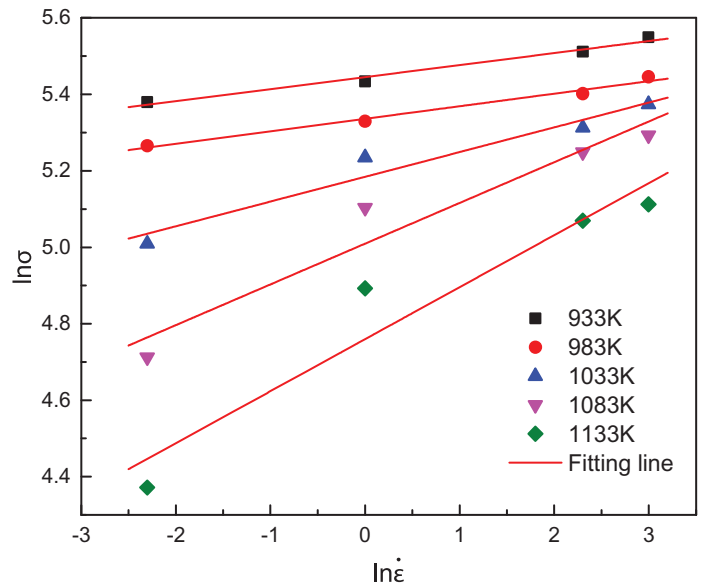

(a)

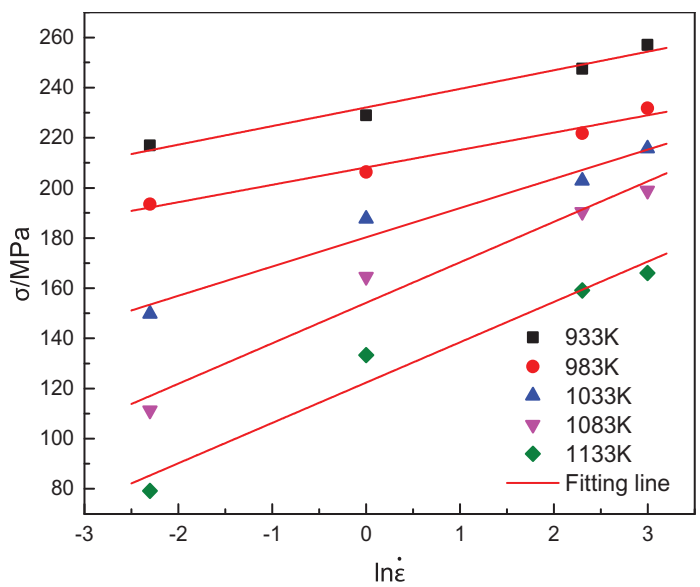

(b)

Figure 16: Relationship between (a) $\ln (\sigma)$ and $\ln (\dot{\varepsilon})$; (b) $\sigma$ and $\ln (\dot{\varepsilon})$.
Then, the value of $\alpha=\beta / \mathrm{n}^{\prime}$ can be obtained.

For all stress levels (including low as well as high stress levels), eq. (25) can be written as follows:

$$
\dot{\varepsilon}=A[\sinh (\alpha \sigma)]^{n} \exp \left(-\frac{Q}{R T}\right)
$$

Taking the natural logarithm of both sides of eq. (31):

$$
\ln [\sinh (\alpha \sigma)]=\frac{\ln \dot{\varepsilon}}{n}+\frac{Q}{n R T}-\frac{\ln A}{n}
$$

For a particular temperature, eq. (32) can be written as:

$$
\frac{d\{\ln [\sinh (\alpha \sigma)]\}}{d(\ln \dot{\varepsilon})}=\frac{1}{n}
$$

The slopes of the lines of $\ln [\sinh (\alpha \sigma)]-\ln \dot{\varepsilon}$ can be applied to determine the value of material constant $n$, which is presented in Figure 17. The value of $n$ is determined by averaging the values of $n$ under different temperatures.

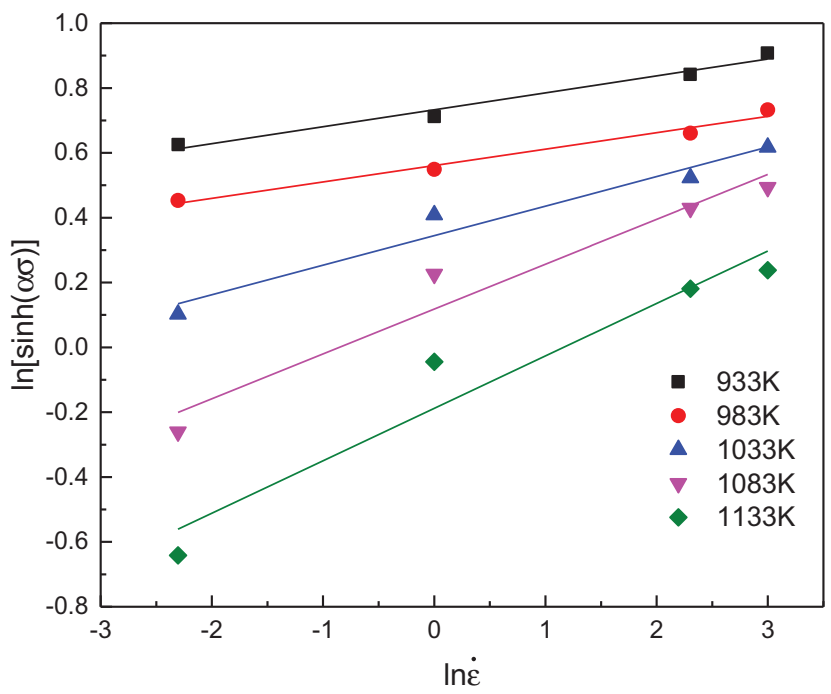

Figure 17: Relationship between $\ln [\sinh (\alpha \sigma)]$ and $\ln \dot{\varepsilon}$.

For a particular strain, eq. (32) can be written as:

$$
\mathrm{Q}=\operatorname{Rn} \frac{d\{\ln [\sinh (\alpha \sigma)]\}}{d\left(\frac{1}{T}\right)}
$$

The slopes of the plot of $\ln [\sinh (\alpha \sigma)]$ and $\frac{1000}{T}$ can determine the value of $Q$, which can be found in Figure 18 ( $Q$ is in $\mathrm{KJ} / \mathrm{mol}$ ). The value of $Q$ is determined by averaging the values of $Q$ under different strain rates. 


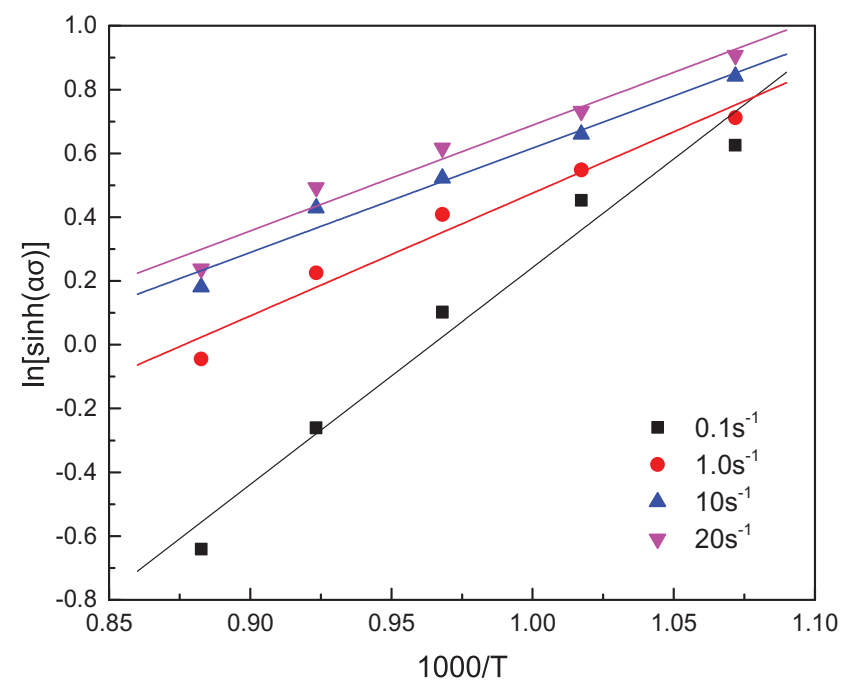

Figure 18: Relationship between $\ln [\sinh (\alpha \sigma)]$ and $\frac{1000}{T}$.

The values of A can be determined from the intercept of $\ln [\sinh (\alpha \sigma)]-\bar{P}$ at a particular strain.

According to previous studies, it is usually assumed that the impact of strain over the flow stress at elevated temperatures was dramatic. Thus, it was overlooked in eqs. (24) and (25). However, the effect of the strain over the material constants (i.e. $\alpha, n, Q$ and $\ln A$ ) is significant in the entire strain range.

As a result, the compensation of the strain should consider the constitutive model and hence to ensure that model can be more accurate. The influence of the strain of the constitutive equation is combined by the assumption that the material constants $(\alpha, n, Q$ and $\ln A)$ are polynomial functions of the strain. As illustrated in eq. (35), it has been found that there is a third-order polynomial to represent the influence of strain on material constants with a good correlation and generalization, as shown in Figure 19. In the meanwhile, the polynomial results of $\alpha, n, Q$ and $\ln A$ of TA2 are provided in Table 5 .

$$
\begin{gathered}
\alpha=C_{0}+C_{1} \varepsilon+C_{2} \varepsilon^{2}+C_{3} \varepsilon^{3}+C_{4} \varepsilon^{4}+C_{5} \varepsilon^{5} \\
\mathrm{n}=D_{0}+D_{1} \varepsilon+D_{2} \varepsilon^{2}+D_{3} \varepsilon^{3}+D_{4} \varepsilon^{4}+D_{5} \varepsilon^{5}+D_{6} \varepsilon^{6} \\
\mathrm{Q}=E_{0}+E_{1} \varepsilon+E_{2} \varepsilon^{2}+E_{3} \varepsilon^{3}+E_{4} \varepsilon^{4}+E_{5} \varepsilon^{5}+E_{6} \varepsilon^{6} \\
\ln \mathrm{A}=F_{0}+F_{1} \varepsilon+F_{2} \varepsilon^{2}+F_{3} \varepsilon^{3}+F_{4} \varepsilon^{4}+F_{5} \varepsilon^{5}+F_{6} \varepsilon^{6}
\end{gathered}
$$

Then the flow stress at a specific strain can be estimated. The hyperbolic sine function is used while the ZenerHolloman parameter is used to express the constitutive equation in the following form:

$$
\sigma=\frac{1}{\alpha} \ln \left\{\left(\frac{Z}{A}\right)^{.7 e x 1 / .7 e x n}+\left[\left(\frac{Z}{A}\right)^{.7 e x 2 / .7 e x n}+1\right]^{.7 e x 1 / .7 e x 2}\right\}
$$

Figure 20 presents the comparison between the predicted and experimental values by strain-compensated Arrheniustype constitutive equation at different processing conditions.

Figure 20 shows that the flow stress estimated by the constitutive equation is in line with the experimental results in the three lower temperatures of 933,983 and $1,033 \mathrm{~K}$. It has a deviation under the two higher temperatures $1,083 \mathrm{~K}$ and 1,133 $\mathrm{K}$ with the lower predicted flow stress compared with the experimental flow stress at high strain rates of 10 and $20 \mathrm{~s}^{-1}$.

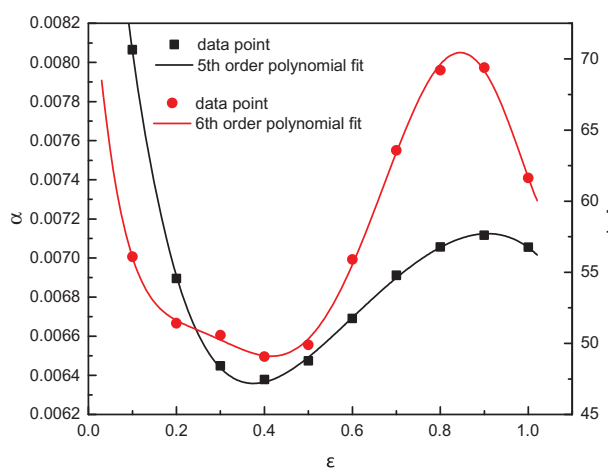

(a)

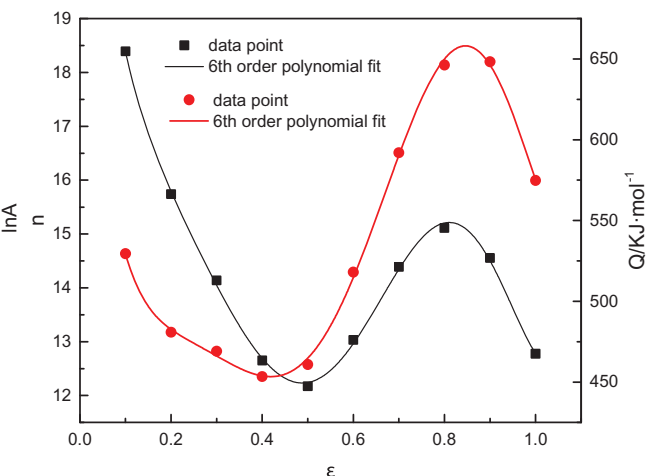

(b)

Figure 19: Variation of (a) $\alpha$ and $\ln A$; (b) $n$ and $Q$ with true strain. 
Table 5: Coefficients of the polynomial for $\alpha, n, Q$ and $\ln A$.

\begin{tabular}{lrrr}
\hline $\boldsymbol{\alpha}$ & $\boldsymbol{n}$ & $\boldsymbol{Q}$ & $\ln \boldsymbol{A}$ \\
\hline$C_{0}=0.0103$ & $D_{0}=25.11695$ & $E_{0}=750.66559$ & $F_{0}=79.06741$ \\
$C_{1}=-0.02948$ & $D_{1}=-111.03566$ & $E_{1}=-4,056.43947$ & $F_{1}=-426.34054$ \\
$C_{2}=0.08042$ & $D_{2}=606.25718$ & $E_{2}=25,413.6202$ & $F_{2}=2,709.35854$ \\
$C_{3}=-0.10141$ & $D_{3}=-2,018.06511$ & $E_{3}=-82,838.39084$ & $F_{3}=-8,842.54727$ \\
$C_{4}=0.06491$ & $D_{4}=3,540.30638$ & $E_{4}=139,387.0193$ & $F_{4}=14,848.62256$ \\
$C_{5}=-0.01769$ & $D_{5}=-2,957.91374$ & $E_{5}=-111,867.4102$ & $F_{5}=-11,893.96422$ \\
& $D_{6}=928.12046$ & $E_{6}=33,786.11744$ & $F_{6}=3,587.47008$ \\
\hline
\end{tabular}

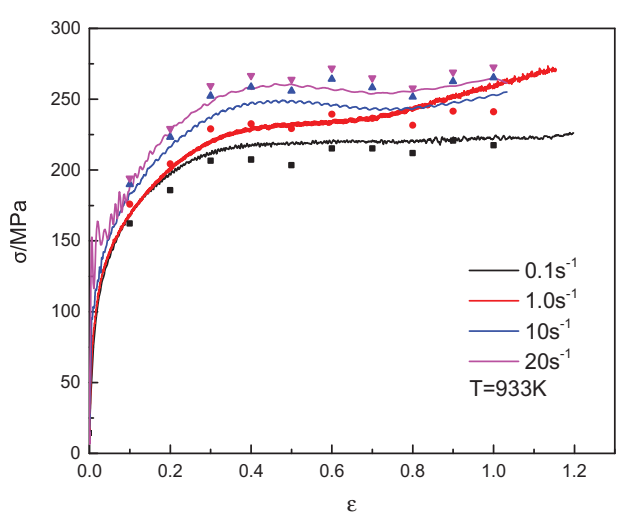

(a)

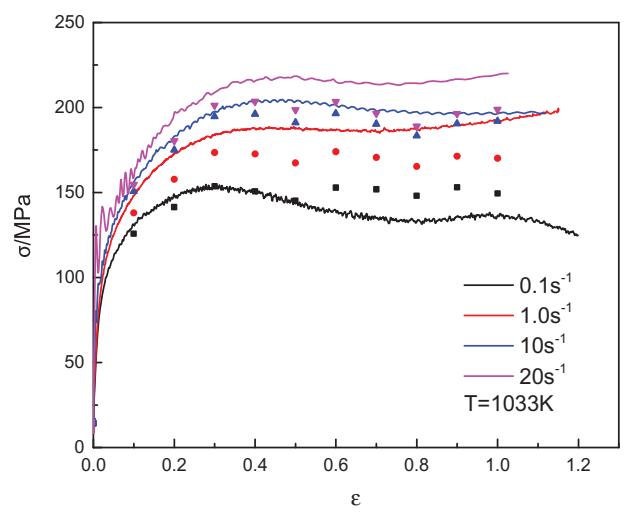

(c)

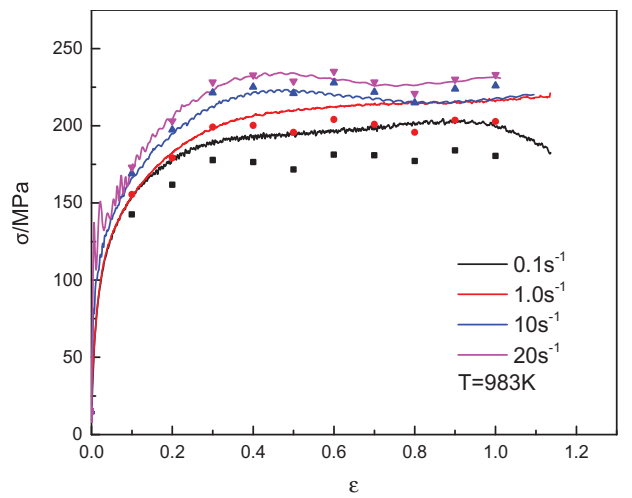

(b)

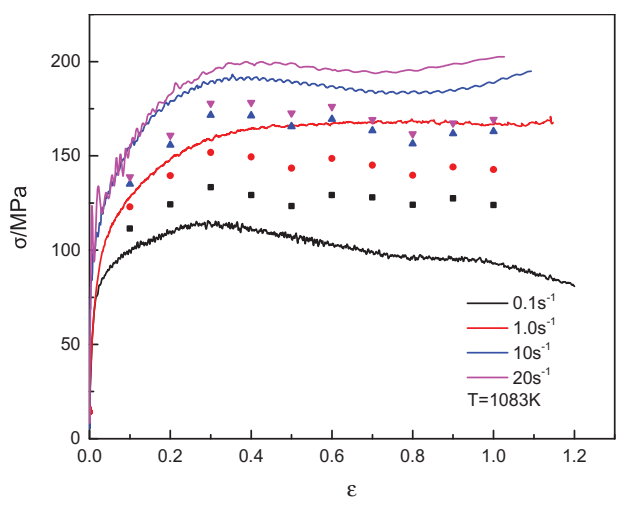

(d)

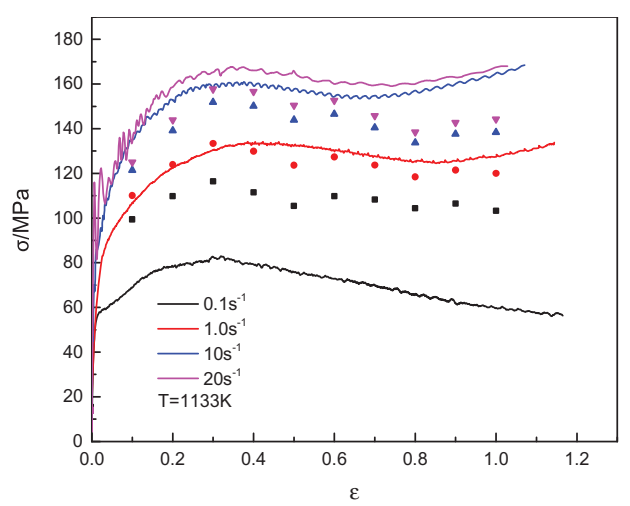

(e)

Figure 20: Comparison between experimental and predicted flow stress using strain-compensated Arrhenius-type equation at the temperatures of (a) $933 \mathrm{~K}$, (b) $983 \mathrm{~K}$, (c) $1,033 \mathrm{~K}$, (d) $1,083 \mathrm{~K}$, (e) $1,133 \mathrm{~K}$. 


\section{Discussion}

According to the calculation results above, it can be observed that the JC model demonstrates good prediction only under the reference temperature, which might be the reason for the fact that the JC model does not take the coupled effects of the strain rate and temperature into consideration. The comparison of the predicted and experimental flow stress has been used to verify the developed modified JC constitutive equation. It can be observed that the predicted flow stress value of the constitutive equation should track the experimental data in most deformation conditions. The experimental data can not be tracked by the predicted flow stress value of the constitutive equation. This is probably because of that the ZA model is applied to analyze the BCC and the FCC under different strain rates and temperatures. However, according to the proposed research, it is a type of $\alpha$-phase hexagonal close-packed commercially pure titanium. Thus, the modified ZA model is not suitable for the materials. At the same time, it is shown from the straincompensation Arrhenius-type model that it can give a good prediction of the elevated temperature flow behavior of TA2 under some deformation conditions. However, a remarkable variation between experimental and calculated flow stress data can also be observed.

Besides, all the results obtained from these four models have variation under some deformation conditions, which is illustrated in Figures 6, 10, 15 and 20. This is probably due to that deformation behavior of the material is highly nonlinear at elevated temperatures and strain rates. The plastic deformation occurs at high temperature and is nonlinear. In contrast, the elastic deformation is linear. There are many factors that can influence the flow stress, which can lead to the low prediction of the models. Additionally, the fitting of the material constants might result in the variation between the experimental and calculated flow stress data. Thus, there are some mistakes that might be introduced over the determination of the materials constant values, which influence the accuracy of the constitutive equation. Meanwhile, there is an increase of the temperature because the deformation heating might lead to a large part of the flow softening, resulting in the lower experimental flow stress data.

The standard statistical parameters are used to verify the accuracy of the described models, such as the correlation coefficient $(R)$ and AARE. Information about the strength of linear relationship between the predicted values and experimental values is provided by the correlation coefficient $(R)$. AARE and $R$ can be expressed as the following:

$$
\begin{gathered}
\operatorname{AARE}(\%)=\frac{1}{N} \sum_{i=1}^{N}\left|\frac{E_{i}-P_{i}}{E_{i}}\right| \times 100 \\
\mathrm{R}=\frac{\sum_{i=1}^{N}\left(E_{i}-\bar{E}\right)\left(P_{i}-\bar{P}\right)}{\sqrt{\sum_{i=1}^{N}\left(E_{i}-\bar{E}\right)^{2} \sum_{i=1}^{N}\left(P_{i}-\bar{P}\right)^{2}}}
\end{gathered}
$$

where $E$ and $P$ are the experimental and predicted flow stresses (MPa), respectively. $\bar{E}$ and $\bar{P}$ are the mean values of $E$ and $P$, respectively. $N$ is the total number of data used in this study.

The comparisons between the predicted data and the experimental flow stresses by the three developed models are presented in Figure 21.

Based on the statistics above, the majority of the data points are located around the fitting line. Under the four constitutive models conditions (strain-compensated Arrhenius-type constitutive model, the modified ZA model, the modified JC model and the JC model), the values of $R$ are $0.938,0.911,0.942$ and 0.771 respectively, while the values of AARE are 9.49\%, 27.3\%, $9.57 \%$ and $24.11 \%$ respectively. It can be observed from the combined results of AARE and $R$ that the straincompensated Arrhenius-type model demonstrates a better correlation between the experimental data and predicted results compared with others.

\section{Conclusions}

A comparative research was made over the capacity of the strain-compensated Arrhenius-type constitutive model, the modified ZA model, the modified JC model and the JC model to describe the elevated temperature flow behavior of TA2 in the temperature range of 933$1,133 \mathrm{~K}$ and a wide range strain rate range of $0.1-20 \mathrm{~s}^{-1}$. According to the results of the research, the following conclusions can be drawn:

(1) The JC and the modified ZA model are not suitable for the estimation of the high-temperature flow behavior of TA2 over the entire range of strain rates, temperatures and strains, while both straincompensated Arrhenius-type and modified JC models can be applied to estimate the flow stress behavior of TA2 at elevated temperatures. 


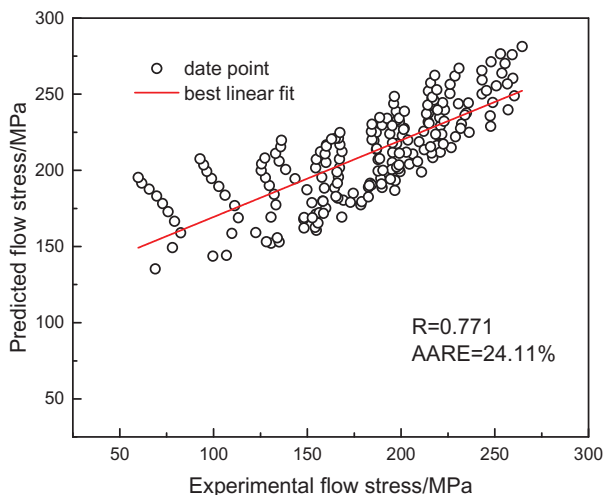

(a)

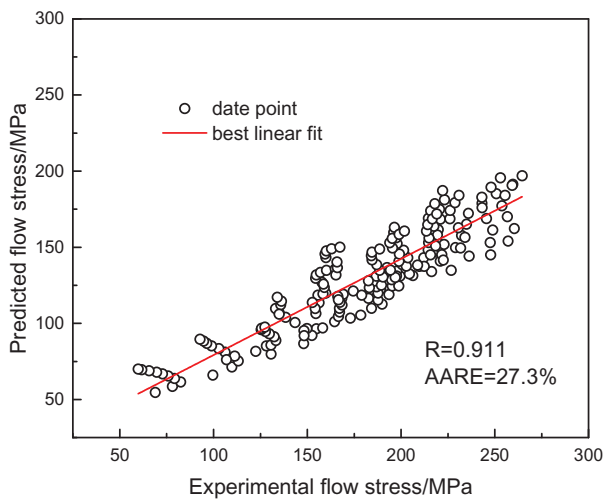

(c)

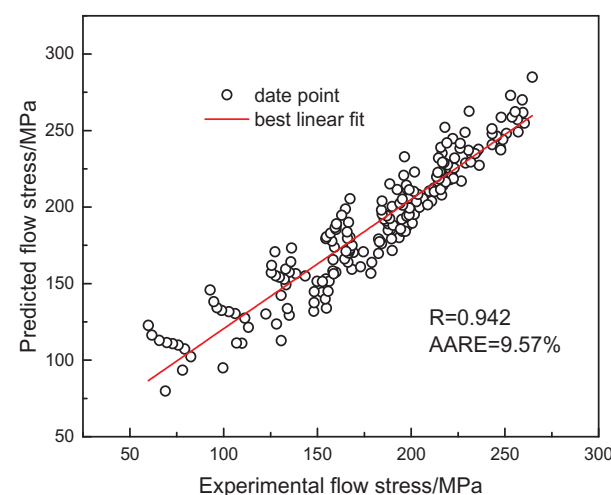

(b)

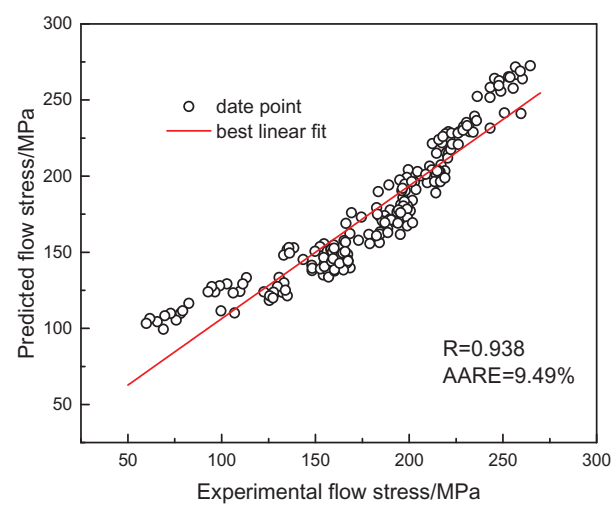

(d)

Figure 21: Correlation between the experimental and predicted flow stress values from (a) Johnson-Cook model, (b) modified Johnson-Cook model, (c) modified ZA model, (d) the strain-compensated Arrhenius-type model.

(2) The predictability of four constitutive equation models was measured about its correlation coefficient $(R)$ and AARE, the results of which suggested that the values of AARE from the strain-compensated Arrhenius-type, modified ZA, modified JC and JC models are $9.49 \%, 27.3 \%, 9.57 \%$ and $24.11 \%$ respectively while the correlation coefficients are 0.938 , 0.911, 0.942 and 0.771, respectively, indicating that the strain-compensated Arrhenius-type model could more accurately represent the elevated temperature flow behavior in the entire processing area.

(3) All of these results obtained from these four kinds of models have dramatic variation in some deformation conditions, the major reasons of which might be that the deformation behavior of the material is highly nonlinear at elevated temperatures and strain rates.

Funding: This work was financially supported by the National Natural Science Foundation of China (Grant 51874226), Planning project of science and technology of Xi'an (Grant 201805033YD11CG17(8)) and the research foundation of Xi'an University of Architecture \& Technology (Grant JC1507).

\section{References}

[1] J.H. Su, Y.W. Han, F.Z. Ren, S.Z. Wei and Z.Q. Chan, Cailiao Rechuli Xuebao., 35 (2014) 196-200.

[2] Z. Zeng, Y. Zhang and S. Jonsson, Mater. Des., 30 (2009) 3105-3111.

[3] Y.Y. Zong, Y.C. Liang, Z.W. Yin and D.B. Shan, Int. J. Hydrogen Energy., 37 (2012) 13631-13637.

[4] H.Y. Li, Y.H. Li, D.D. Wei, J.J. Liu and X.F. Wang, Mater. Sci. Eng., A., 530 (2011) 367-372.

[5] P. Changizian, A. Zarei-Hanzaki and A.A. Roostaei, Mater. Des., 39 (2012) 384-389.

[6] C. Li, M. Wan, X.D. Wu and L. Huang, Mater. Sci. Eng., A., 527 (2010) 3623-3629.

[7] Y. Han, G. Qiao, J.P. Sun and D. Zou, Comput. Mater. Sci., 67 (2013) 93-103.

[8] D. Samantaray, S. Mandal and A.K. Bhaduri, Mater. Des., 31 (2010) 981-984.

[9] H.J. Mcqueen and N.D. Ryan, Mater. Sci. Eng., A., 322 (2002) 43-63.

[10] Y.J. Qin, Q.L. Pan, Y.B. He, W.B. Li, X.Y. Liu and X. Fan, Adv. Manuf. Process., 25 (2010) 527-533. 
[11] Z.W. Yuan, F.G. Lin, H.J. Qiao, M.L. Xiao, J. Cai and J. Li, Mater. Sci. Eng., A., 578 (2013) 260-270.

[12] S. Varoutis, S. Naris, V. Hauer, C. Day and D. Valougeorgis, Mater. Sci. Eng., A., 527 (2009) 328-333.

[13] J. Lin and Y. Liu, J. Mater. Process. Technol., 143 (2003) 281-285.

[14] X. He, Z. Yu, G. Liu, W. Wang and X. Lai, Mater. Des., 30 (2009) 166-169.

[15] D. Samantaray, S. Mandal and A.K. Bhaduri, Comput. Mater. Sci., 47 (2010) 568-576.

[16] A.K. Gupta, V.K. Anirudh and S.K. Singh, Mater. Des., 43 (2013) 410-418.

[17] A. Abbasi-Bani, A. Zarei-Hanzaki, M.H. Pishbin and N. Haghdadi, Mech. Mater., 71 (2014) 52-61.

[18] Y.C. Lin and X.M. Chen, Mater. Des., 32 (2011) 1733-1759.
[19] D. Samantaray, S. Mandal, U. Borah, A.K. Bhaduri and P.V. Sivaprasad, Mater. Sci. Eng., A., 526 (2009) 1-6.

[20] H. Zhan, G. Wang, D. Kent and M. Dargusch, Mater. Sci. Eng., A., 612 (2014) 71-79.

[21] C.M. Sellars and W.J. Mctegart, Acta Metall., 14 (1966) 1136-1138.

[22] P. Geng, G. Qin, J. Zhou and Z. Zou, J. Manuf. Process., 32 (2018) 469-481.

[23] Y.C. Lin, M.S. Chen and J. Zhong, Comput. Mater. Sci., 42 (2008) 470-477.

[24] Y.B. Tan, Y.H. Ma and F. Zhao, J. Alloys Compd., 741 (2018) 85-96.

[25] Y. Zhang, H.L. Sun, A.A. Volinsky, B.H. Tian, K.X. Song, B.J. Wang and Y. Liu, Vacuum., 146 (2017) 35-43. 